\title{
ALTERNÂNCIA LINGUÍSTICA \\ NA SALA DE AULA DE \\ ESPANHOL: A GESTÃO DE \\ LÍNGUAS NA PRÁTICA
}

Hermínia Ribeiro1

Cibele Krause-Lemke2

Resumo: Neste artigo analisamos fragmentos de aulas de espanhol no Ensino Médio de uma escola pública da região de Irati, PR, em um contexto sociolinguisticamente complexo, constituído por falantes de Língua de Herança (Cf. MELLO-PFEIFER, 2018), com destaque para o ucraniano e o polonês. Buscamos analisar a gestão de línguas (Cf. BERGER, 2015), a partir da alternância linguística (NUSSBAUM, 1998), em sala de aula, com vistas a entender o papel destinado às línguas que permeiam o contexto familiar e escolar dos falantes. São dados integrantes de uma pesquisa de Mestrado de tipo etnográfica (Cf. ANDRÉ, 1995), com viés qualitativo interpretativista. Por meio das análises evidenciamos a necessidade de formação de professores voltada à educação linguística para atuar em contextos multilinguísticos, o que fomentaria práticas docentes condizentes à realidade linguística e cultural em que a escola está inserida.

Palavras-Chave: Alternância Linguística. Ensino de Espanhol. Gestão de Línguas.

\section{LINGUISTIC ALTERNANCE IN THE SPANISH CLASSROOM: LANGUAGE MANAGEMENT IN PRACTICE}

\begin{abstract}
In this article we analyze fragments of Spanish classes in high school at a public school in the region of Irati, PR, in a sociolinguistically complex context, consisting of speakers of the Heritage Language (Cf. MELLO-PFEIFER, 2018), with emphasis on Ukrainian and the polish. We seek to analyze the language management (Cf. BERGER, 2015), based on linguistic alternation (NUSSBAUM, 1998), in the classroom, with a view to understanding the role destined for the languages that permeate the family and school context of the speakers. They are data that are part of a Master's research of an ethnographic type (Cf. ANDRÉ, 1995), with qualitative interpretive bias. Through the analyzes, we highlighted the need for teacher training focused on language education to work in multilingual contexts, which would encourage teaching practices consistent with the linguistic and cultural reality in which the school is inserted.
\end{abstract}

Keywords: Linguistic Alternation. Spanish teaching. Language Management.

1 Mestre em Letras, Interface entre Língua e Literatura, da Universidade Estadual do Centro-Oeste (UNICENTRO). E-mail: herribeiroic@gmail.com.

2 Doutora em Educação pela Universidade de São Paulo. Professora do Departamento de Letras e dos Programas de PósGraduação de Mestrado nas áreas de Educação e de Letras, na UNICENTRO. E-mail: cibelekl@gmail.com. 


\section{Palavras iniciais}

A heterogeneidade cultural e linguística que marca a constituição da nação brasileira se reflete por todos os estados do país, em suas cidades e comunidades. Essa característica advém, primeiramente, das comunidades autóctones (indígenas) e suas línguas que aqui residiam antes mesmo da chegada dos portugueses e da vinda forçada dos povos escravizados com suas línguas e culturas. A essa heterogeneidade soma-se nova diversidade linguística e cultural vinda com o início das ondas migratórias que para cá trouxerem novos povos fugindo de repressões políticas, condições sociais e econômicas vivenciadas em seus países de origem. Muitos desses imigrantes foram distribuídos pelas várias regiões do Brasil, principalmente a região Sul, onde está situada a cidade de Irati, Paraná, contexto que abriga a escola participante da pesquisa.

De acordo com os estudos de Krause-Lemke (2010), Jacumasso (2009), e outros pesquisadores que analisam contextos que se referem à diversidade linguística, explana-se que o estado do Paraná concentra grande parte da imigração de eslavos, orientais, germânicos e italianos, dentre outros, que ainda hoje mantêm algumas das diferentes línguas.

Pereira e Costa (2007) expõem que esta complexidade linguística tem implicações no momento da escolarização dos sujeitos, em decorrência do descompasso entre a língua portuguesa, que permeia todas as práticas escolares, e a língua trazida de casa pelos aprendizes, além de uma variedade de base rural do português, logo, distante daquela privilegiada pela escola. A partir disso, pontuam que tais línguas não têm espaço garantido na escola, portanto, têm seus usos inviabilizados e, muitas vezes, são estigmatizadas, fato que pode cooperar para seu apagamento. Ainda assim, podemos dizer que um movimento contrário pode surgir: o de afirmação de uma identidade linguística e cultural, como propõe Hall (2006). A escola funciona assim como um ponto de encontro entre as tradições, os costumes, as crenças, os valores e as línguas dos alunos, condições que exigirão maior preparo dos profissionais inseridos no contexto, dentre eles, os professores.

\section{Alternância linguística}

A alternância linguística é um fenômeno entendido enquanto o emprego de duas línguas dentro de um mesmo discurso, de uma frase ou sintagma, conforme expõe Poplack (1980). Embora se fale em alternância de línguas, Nussbaum (1991) explana que em cada comunidade de fala existem diferentes variedades de línguas que constituem o repertório linguístico dos falantes. Tal repertório inclui os dialetos (sociais ou regionais), os registros, mas também, códigos profissionais, variedades para falar com crianças, etc., que os falantes ativam a depender das relações sociais nas quais estão inseridos. Segundo a autora, as formas de comunicação de uma comunidade linguística incluem, ainda, a diversidade de estratégias interativas que servem para estabelecer, manter e regular as relações entre seus membros.

Nesse sentido, podemos entender a sala de aula de espanhol como Língua Estrangeira (e não só ela) enquanto uma micro comunidade de fala, pois, assim como pontua Mozzillo (2005), nesse espaço sistemas linguísticos diferentes entram em contato o tempo todo, tais como: a língua materna do professor e dos alunos, que pode não ser a mesma, a Língua Estrangeira em estudo, bem como as demais línguas conhecidas pelos componentes da escola e, acrescentamos aí, as variedades de cada língua.

Grosjean (1982, apud MOZZILLO, 1997) elenca os motivos mais comuns para que a alternância aconteça, a saber: suprir uma necessidade de vocabulário, de marcador discursivo; 
continuar a conversa na última língua empregada; citar alguém; especificar o interlocutor; qualificar a mensagem, tornando-a mais ampla ou dando-lhe ênfase; personalizar a mensagem, especificando o envolvimento do falante; marcar a identidade com o grupo, demonstrando solidariedade; transmitir intimidade, fúria, aborrecimento; excluir alguém da conversa; modificar o papel do falante, aumentando seu status ou outorgando-lhe maior autoridade.

Com base nisso, torna-se evidente que a alternância não constitui uma mistura agramatical de duas línguas não totalmente dominadas, mas uma estratégia comunicativa que é sinal de habilidade utilizada por bilíngues com o objetivo de transmitir informação linguística e social (Cf. Mozzillo, 1997). A partir dessas informações, entende-se que a alternância pode ocorrer em momentos diferenciados e com funções também diferenciadas a depender da situação sociointerativa em que se encontram os falantes de duas línguas ou mais, como é o caso da realidade do contexto em estudo na qual a maioria dos alunos afirmou falar uma língua diferente da oficial. Neste sentido, os alunos e professora podem se valer de diferentes estratégias ao efetivar a alternância linguística.

De acordo com Krause-Lemke (2010), embasada nos estudos de Laranjeira (2005), a alternância pode ser classificada como emblemática, interoracional, e intraoracional.A primeira acontece quando o falante usa palavras soltas e desconectadas dentro da oração, em que não é exigido um conhecimento aprofundado das línguas em questão. No segundo tipo, interoracional, acontece a alternância entre uma língua e outra, exigindo um bom conhecimento de ambas as línguas por parte do falante. A alternância do tipo intraoracional acontece dentre de uma mesma oração, neste caso, há uma mescla entre as línguas.

No campo da Sociolinguística, segundo Krause-Lemke (2010), podemos falar de dois tipos de alternância: comutação e alternância de línguas.
No primeiro caso, Nussbaum (1998) explana que na alternância está implicada uma mudança em um dos parâmetros que definem o contexto. Em aulas de língua estrangeira, podemos entender tais caracterizações como, por exemplo, quando o professor usa uma língua para sinalizar aos alunos o fim ou início da aula bem como a mudança de uma atividade didática. Logo, "A comutação de língua implica uma negociação da língua base da interação, em outras palavras, uma proposta por parte de alguns dos interlocutores para mudar a língua que foi escolhida para o desenvolvimento de determinada atividade" (KRAUSE-LEMKE, 2010, p. 45).

Como veremos nas análises dos dados, este tipo de alternância torna-se comum na dinâmica da sala de aula do contexto, porém, tal fenômeno restringe-se a alternâncias entre o português e o espanhol, quando a professora opta pelo uso de uma ou outra língua durante a explicação de uma atividade, introdução e finalização das aulas. O mesmo processo não contempla o uso das línguas de herança pelo fato de a docente não conhecêlas. Como se nota, este tipo de alternância implica uma negociação da língua base, sinalizando a preferência linguística dos participantes bem como a sinalização de uma identidade.

No segundo caso, chamado de alternância de línguas, ao contrário da comutação, não há uma mudança contextual. Neste caso, trata-se mais de um uso bi/multilíngue, sem a negociação da língua base ou dominante na qual se desenvolve a atividade comunicativa. Temos como exemplo deste fenômeno nas aulas de língua estrangeira momentos em que há o uso simultâneo tanto da língua em estudo quanto da língua compartilhada por todos os participantes da interação, neste caso, entre o espanhol e o português. Este tipo de alternância só é possível quando não há problemas de entendimento entre todos. 
Em contextos de aprendizagem de línguas nos quais as competências linguísticas dos alunos são desiguais, Krause-Lemke, embasa nos estudos de Py (1991; 1995), explana sobre a importância de distinguirmos dois tipos de alternância, quais sejam: exolíngues e bi/multilíngues. No primeiro caso, exolíngues, estão as alternâncias relacionadas a problemas de comunicação, de onde decorrem ajustes entre as competências necessárias para resolver uma atividade ou entre as competências linguísticas entre os participantes. Isso significa que no processo interacional, havendo dificuldades de entendimento, há que se encontrar e escolher uma mesma língua comum entre todos, que disponha de meios para que os problemas sejam sanados e assim, as atividades e a comunicação possam ser entendidas e realizadas por todos.

Esse fenômeno acontece quando, por exemplo, são detectados problemas nas interações entre os participantes, ou ainda, quando o professor percebe que seus alunos não estão entendendo a explicação na língua alvo pelo fato de que muitos podem não ter a competência linguística em dada língua, então, passa-se a alternar entre uma língua e outra para que o objetivo seja atingido. Quando essa ajuda parte do professor ou de outra pessoa, denomina-se heterofacilitação. Quando quem se ajuda é o próprio aluno, seja para compreender ou produzir algo na língua, por meio da mudança de língua, denomina-se autofacilitação.

As de segundo tipo, as alternâncias bil multilíngues, não condizem às diferenças entre competências linguísticas e dificuldades de entendimento na comunicação, mas estão ligadas ao número de línguas de que os falantes dispõem, em que se lança mão deste conhecimento a mais durante as interações. Segundo Krause-Lemke (2010), tais alternâncias servem para citar alguém ou algo dito; para evocar um conhecimento compartilhado entre todos; para rir, fazer brincadeiras, etc.
No contexto estudado, ambos os tipos de alternâncias podem permear as aulas de língua espanhola, em que se torna comum o uso de mais de uma língua, a língua alvo e a língua oficial, quando a professora percebe que necessita adotar estratégia e recursos advindos das duas línguas para se fazer entender. Além disso, as alternâncias se estendem às demais línguas do contexto, usadas entre os estudantes com funções diversas.

Diante dos argumentos expostos e conforme apontamos no início deste tópico, a escolha de uma variante em detrimento de outra, ou da não alternância, não acontece por acaso, ela expressa significação social, ou seja, há interesses, motivações e propósitos pertencentes ao processo de comunicação, como expostos nos estudos de Mozzillo de Moura(1997), Mozzillo (2008) bem como nos estudos de Krause-Lemke (2010).

Conforme Myers-Scotton (1993, apud MOZZILLO, 2008), tanto o locutor quanto o interlocutor pressentem, em razão de suas competências comunicativas, que a escolha de uma variante linguística em detrimento de outra expressa significado social. Tal fato, segundo a autora, revela que durante a alternância também há uma negociação das identidades dos participantes da interação. Frente às colocações da autora, podemos dizer que os usos linguísticos e suas alternâncias, conscientes ou não, podem marcar uma posição social e política. Acreditamos, a partir do que foi exposto até o momento, ser indispensável um olhar criterioso, principalmente, do professor que atua em contextos permeados pelo fenômeno, pois, muitas vezes, há preconceitos camuflados diante da alternância linguística, ligados ao conceito de pureza da língua. Passamos agora a tratar da gestão de línguas enquanto um posicionamento político frente às línguas que se buscam adotar durante a comunicação. 


\section{Gestão de línguas}

Para tratar do termo gestão de línguas, tomamos embasamento nas propostas de Spolsky (2016), de políticas linguísticas, bem como nos estudos de Krause-Lemke (2010) e Feix (2018), dentre outros estudiosos que tratam do tema de gestão de línguas em contextos multilíngues. Podemos citar como a forma mais óbvia de gestão as políticas linguísticas baseadas em crenças da homogeneidade linguística brasileira, aplicadas em leis, ou seja, a gestão que previu o lugar das línguas na sociedade brasileira se deu através de estratégias e práticas elaboradas em um nível macro, propondo intervenções de longo alcance.

No entanto, temos ainda, indivíduos que operam em nível micro. Temos, neste caso, como exemplo de gestão de línguas o domínio familiar, quando, por exemplo, pais imigrantes utilizam vários mecanismos para manter suas Línguas de Herança ou para persuadir seus filhos a aprender uma nova língua, ou ainda, a sala de aula, onde a professora exerce autoridade e poder, e intervém sobre os usos linguísticos, promovendo ou silenciando línguas. Como se nota, a gestão de línguas tem como finalidade ocasionar mudanças, funcionando como exercício de poder, seja das mãos do Estado, ou de agentes menores. Podemos entender, desta forma, que toda ação humana sobre a língua é um feito político, assim, a gestão de línguas é a Política Linguística na prática.

A gestão de línguas estudada nesta dissertação corresponde àquela desenvolvida no domínio escolar enquanto espaço de interação entre participantes que trazem consigo suas práticas e crenças linguísticas, advindas de uma sociedade complexa e cada vez mais multilíngue, portanto, o domínio mais complexo de todos (Cf. SPOLSKY, 2016). Nesse espaço, as duas principais categorias de participantes, são a professora de espanhol do local e seus alunos.
Os alunos, cujas práticas e crenças linguísticas podem ser passíveis de modificação (Cf. Spolsky, 2016), trazem uma bagagem linguística e cultural diversa, e em sala de aula encontram-se com a segunda categoria de participantes, os professores (em nosso estudo, a professora de espanhol) encarregados no processo de modificação, embora reconheçamos que estes papéis se invertam a depender do contexto em que se inserem tais participantes, falantes ou atores.No tocante ao segundo grupo, Spolsky nos alerta sobre o cuidado com o tratamento a eles direcionado tendo em vista que estes variam em múltiplas dimensões, como por exemplo, idade, gênero, nível de habilidade, e motivação bem como na variedade ou nas variedades de língua que conhecem e em seus níveis de proficiência, pois:

Sua experiência no domínio do lar, na
vizinhança, e em outros lugares os terá
apresentado a diversas práticas linguísticas,
desenvolvido neles crenças sobre linguagem
e valores que eles atribuem às variedades
linguísticas, e os expostos a várias tentativas de
modificar suas práticas e crenças linguísticas.
Portanto, não estamos lidando de modo
algum com uma tabula rasa, já que as crianças
vão para a escola com valores, habilidades e
comportamentos linguísticos estabelecidos
(SPOLSKY, 2016, p. 39).

O segundo grupo, segundo Spolsky, também pode ser múltiplo em suas dimensões, trazendo para dentro do espaço escolar suas práticas e crenças linguísticas bem como sua competência linguística. No entanto, quando há um desequilibro entre os grupos de participantes, há o que ao autor denomina de lacuna linguística, cujo fenômeno pode resultar numa gestão de línguas permeada por uma política linguística excludente, conforme pontua Altenhofen (2004). A fim de expandir o entendimento do termo gestão de línguas com foco na escola, buscamos suporte teórico também nos estudos de Krause-Lemke (2010). Nessa perspectiva, a autora destaca que a gestão de línguas em sala de aula é importante em dois sentidos: 
[...] em primeiro lugar, ajuda os participantes a organizar o que acontece naquele espaço, ao mesmo tempo em que lhes permite construir e negociar diferentes identidades. Em segundo, a gestão das línguas pelos participantes pode ser compreendida como parte do processo de aprendizagem, oportunizando, assim, o incremento de sua capacidade plurilíngue (KRAUSE-LEMKE, 2010, p. 49).

Partindo disso, com base nos argumentos acima, tendo em mente que nosso estudo envolve uma escola inserida em um contexto cultural e linguisticamente complexo, entendemos que as práticas linguísticas em sala de aula nem sempre se efetivarão da mesma maneira. Ou seja, as línguas são gerenciadas em dado ambiente conforme as necessidades dos alunos, mas, principalmente, dos professores.

Tendo em conta esses argumentos, segundo a autora, muitos estudos na área de segundas línguas e línguas estrangeiras, postulam que, mais que uma competência linguística, em tais situações de emprego de mais de uma língua, os falantes desenvolvem o que Coste et. al (1997) e Moore (2009) denominam competência plurilíngue, que se desenvolve a partir da necessidade que tais falantes têm de administrar suas línguas em contextos e situações diversas, dentre elas, a sala de aula.

A gestão de línguas enquanto forma de discutir Política Linguística, pode ser usada para variados fins, dentre eles, como já mencionado anteriormente, a negociação entre diferentes identidades, bem como sua manutenção. Tais processos serão mantidos através das alternâncias linguísticas descritas acima, como veremos mais claramente durante as nossas análises dos dados obtidos através da gravação em áudio das aulas de espanhol.

\section{Discussão e análise dos dados}

O foco deste tópico é analisar as práticas linguísticas em sala de aula com vistas a entender com mais profundidade o processo de gestão de línguas adotada em dado ambiente. Tais exercícios nos possibilitarão identificar quais os papéis destinados a cada uma das línguas a que os falantes têm acesso. Salientamos que os nomes dos participantes são pseudônimos usados como forma de preservar suas identidades. Como forma de direcionamento para as análises dos registros etnográficos gerados a partir das gravações das aulas de espanhol e a gestão das línguas em dado ambiente, nos perguntamos: 1) Qual língua o professor usa em suas aulas? 2) Em que momentos se usa o português durante as aulas? E o espanhol? E as línguas de herança? 3) Quais são os papéis destinados às diferentes línguas em sala de aula?

Salientamos que nosso objetivo não é apenas demarcar as alternâncias linguísticas e conceituálas dentro de nomenclaturas, mas, entendermos as motivações para que tenham surgido, bem como analisar quais são as suas funções dentro de uma situação sociocomunicativa. Assim, entendemos que a alternância de línguas não corresponde somente à troca de códigos durante uma interação, mas funciona como uma prática social em que os participantes imprimem, neste processo, seus posicionamentos, crenças, valores, e identidades. Desta forma, passamos ao estudo do primeiro fragmento.

$O$ primeiro fragmento a ser analisado corresponde a dados obtidos em uma das aulas assistidas na turma do primeiro ano. Como veremos, durante as explicações acerca do conteúdo programático, a professora opta pelo uso corrente do português:

\section{Fragmento 1 (linhas 1 a 26)}

1. Professora: não, não copiem, só deixem eu escrever daí vocês copiam

2. essas palavras aqui, soltero, viudo, separado, divorciado, que que são essas 
3. palavras? (Lista de palavras é exposta na lousa)

4. Clara: estado civil?

5. Felipe: Estado civil

6. Professora: estado civil! Essa palavra $\uparrow$ estado, vem de qual verbo?

8. Alceu: de estar!

9. Professora: estar $\uparrow$ Então em espanhol eu uso o verbo estar para dizer qual

10. estado civil que a pessoa está. Esta soltero, está casado, está viudo, está

11. divorciado o está separado. E em português como que eu digo?

12. Diogo: tá solteiro, tá separado

13. Professora: é (.) casado, é solteiro!

14. Diogo: Ah, é!

15. Professora: é casado, é solteiro (: : ) né! É solteiro, é viúvo, né. Ou eu posso

16. utilizar o estar também, né. Nossa já está casado? Ou então: nossa, tão novo e

16. já é viúvo! né? (. ) Então a gente pode usar os dois verbos né, o verbo estar e o

17. verbo ser. No espanhol eu só uso o verbo estar. Entendido $\uparrow$ ? Podem copiar,

18. então! (..)

19. Mário: quanto espaço é pra dexá?

20. Professora: qual que é a diferença entre separado e divorciado?

21. Alceu: separado é que tá ... (não termina a resposta)

22. Diogo: divorciado é no papel e separado é só na...

\section{Mário: compromisso! (Risos)}

24. Professora: então separado é quando está separado de corpos (alunos riem)

25. quando sai de casa, um deles sai da casa, e divorciado quando se separam no

26. papel.
Como se nota, os registros condizem ao estudo acerca da caracterização do "estado civill" de um indivíduo, em língua espanhola. Para esta atividade, a docente expôs uma lista de palavras na lousa, conforme indicam as linhas 1 e 2 e, a partir disso, passou a contextualizar e explicar a atividade em foco tendo como suporte a pergunta reflexiva iniciada na linha 2, finalizada na linha 3.

A linha 4 revela a resposta efetuada por Clara ao questionamento da professora, porém, permeada de incertezas, visíveis a partir da interrogação à sua própria resposta. $\mathrm{Na}$ linha 5 , um colega de turma fornece a resposta correta, confirmada e aceita pela professora na linha seguinte, momento em que, a partir da entonação da voz usada para dar ênfase ao verbo "estar", busca-se maior atenção e reflexão por parte dos estudantes. Tal fato enfatiza a necessidade de atenção dos alunos e reflexão acerca da função e uso do verbo para marcar o estado civil de uma pessoa.

Esse gesto reflexivo contempla o estudo da variação linguística entre os idiomas, ou seja, a comparação entre as maneiras de se referir ao estado civil em espanhol e português, conforme se nota nas linhas 10 e 11.

No turno 12, Diogo responde ao questionamento efetuado nos turnos anteriores, mas, seguindo a estrutura da Língua da Estrangeira, exposta nas linhas 10 e 11 . O aluno é corrigido pela docente (linha 13) ao informá-lo de que a resposta desejada para se mencionar o estado civil de um indivíduo, em português, é validada com o emprego do verbo "estar" no presente do indicativo.

Tendo em vista que em português o estado civil de um indivíduo pode ser expressado com o emprego do verbo "ser" ou do verbo "estar", conjugados e articulados na oração a depender do grau de formalidade da interação bem como a partir da formulação da pergunta efetuada pelo interlocutor, e levando em consideração a versatilidade de uma língua, vemos que nos turnos 
15, 16, e 17, a afirmação e posicionamento da profissional é rearticulado e corrigido.

Esse movimento de autocorreção efetivado pela docente propicia, mais uma vez, a discussão e reflexão acerca da variação linguística, agora, com ênfase na língua oficial, mesmo que de maneira sutil. Assim, a professora passa a dar exemplos das possibilidades de uso da língua portuguesa frente ao único modo de uso da língua estrangeira para expressar as mesmas informações, possibilitando aos alunos o entendimento e o conhecimento das possibilidades de usos de suas próprias línguas bem como da exposição da realidade linguística brasileira. Essas reflexões metalinguísticas, ora feitas pela docente, ora pelos estudantes, subsidiadas por usos linguísticos em português, continuam sendo contextualizadas nos turnos seguintes.

As práticas linguísticas presentes no fragmento interacional acima nos mostram as nuances de uma sala de aula de Língua Estrangeira, pois, como visto, os falantes lançam mão de estratégias para se fazerem melhor entender a depender dos interlocutores e da situação sociocomunicativa.

Tal afirmação ganha suporte a partir das atitudes de alunos, como veremos no fragmento abaixo (Fragmento 2), que assim como Mário, têm conhecimentos das possibilidades de usos de seus conhecimentos linguísticos a mais, e os fazem a depender de seus objetivos e dos interlocutores com quem interagem, ou ainda, com base na atitude docente que, para atingir um nível satisfatório de explicação e compreensão do emprego do verbo "estar" em ambas as línguas, lança mão de estratégias para administrar as línguas em sala de aula: espanhol usado somente para contextualizar o conteúdo a ser ensinado e português como língua suporte à explicação e organização de toda a aula.

Nesse viés, por julgar que nem todos compreenderiam suas explicações em língua espanhola, em decorrência de muitos alunos ainda não terem tido contato com o idioma em anos escolares anteriores, a docente percebe a necessidade de ajustes de usos das línguas ao prever que sua explicação seria melhor compreendida em português. Sendo assim, opta-se pelo uso deste idioma em sala, por ser a língua em comum entre ela e seus alunos. O espanhol, por sua vez, conforme linhas 2, 10 e 11, constitui-se em língua objeto de estudo.

Mesmo que o enquadre interacional exponha que tanto a língua oficial quanto a Língua Estrangeira bem como usos de variedades do português constituam a interação, nesta sala de aula, as alternâncias entre as línguas estas são perpassadas pelo uso constante do português quando se percebem empecilhos na comunicação. Assim, a gestão das línguas é subsidiada por alternâncias linguísticas de tipo exolíngues e pelo exercício de heterofacilitação, oportunizado por parte da professora, em decorrência de ajustes linguísticos necessários em decorrência de diferenças encontradas entre os saberes linguísticos dos falantes.

A partir da análise desse primeiro fragmento, podemos visualizar o uso majoritário do português em sala de aula mesmo que no contexto em estudo circulem, além da língua oficial e suas variedades, tanto a Língua Estrangeira quanto as Línguas de Herança locais, conforme aponta a linha 29 do fragmento 2, a ser analisado a seguir.

\section{Fragmento 2 (linhas 27 a 32)}

27. Maria: ah! O xxx tá separado né? (Alunos conversando)

28. João: ui que inferno (Ri)

29. Mário: é, né, fayno, fayno, né! (Alunosriem)

(Tradução: fayno/ файнo: bonito, bonito)

30. Marcos: fazê o quê, né? (Risos) 
31. Maria: sim, XXX (fala muito baixo e ri)

32.Professora: Shiu! Quietos!!!

Os registros acima pertencem ao fragmento analisado anteriormente, no qual pudemos observar alternâncias linguísticas entre o português e o espanhol, em que a primeira língua sobressaiu à estrangeira por conta da necessidade de a docente se fazer melhor entender em sua explicação.

Ao continuarmos analisando o referido enquadre interacional acima (2) percebe-se que a linha 27 apresenta um desvio na atenção dos alunos quanto à explicação da professora. Neste momento, a partir da temática da aula, entra em foco uma conversa paralela na qual o assunto abordado e debatido por quatro alunos, refere-se ao estado civil de um morador da comunidade. Grande parte da interação é sustentada pelo português mas, a linha 29, no entanto, apresenta uma quebra na articulação linguística em uso, e uma das línguas do contexto, o ucraniano, aparece durante a discussão, nos dando indícios da realidade linguisticamente diversa que constituinte do local.

Como se evidencia no fragmento 2, a exposição da língua de herança surge a partir de um momento mais descontraído, sem ligações explícitas com o conteúdo programático e sem incentivo ou intervenções explícitas da professora em favor de práticas linguísticas que orientem a visibilidade das línguas de herança na sala de aula, ao contrário, tal movimento é efetivado pelos interesses discentes, assim como acontece no fragmento 3, a ser analisado posteriormente.

As afirmações feitas com base no fragmento 2 acerca do surgimento da língua de herança em sala de aula, não implicam imposições de que a manifestação desse idioma em ambiente escolar tenha elos com a disciplina em si, pois, embora não se tenha problematizado o conteúdo em foco nas línguas do contexto, acreditamos que pelo fato de estar em voga a discussão entre as diferenças linguísticas entre o português e o espanhol (linhas 15 a 17), tal processo levou o aluno a demonstrar e legitimar seu conhecimento em outra língua.

Embora o objetivo possa ser o de expor seu conhecimento no idioma ucraniano, vemos também que o propósito, levando em conta o comportamento dos participantes dessa interação, vincula-se a um momento de descontração entre os colegas de turma.

O surgimento da língua eslava em sala de aula transparece uma alternância linguística que não se explica por diferenças entre as competências linguísticas dos falantes, pois, não há indícios de incompreensão de Mário acerca do conteúdo trabalhado, tão pouco sobre as explicações da professora ou ainda, do conteúdo da conversa entre os colegas.

Nesse sentido, a alternância linguística entre o ucraniano e português se explica pela necessidade de o aluno, como já dito, manifestar seu saber a mais, caracterizando as alternâncias de tipo bilingues/multilíngues, conforme Nussbaum (1991), usadas, dentre outros fatores, para fazer brincadeiras, como é o caso de Mário, que usa a língua eslava para interagir de forma descontraída com os colegas, levando-os ao riso.

Tal ocorrência também nos permite dizer que a língua eslava exprime proximidade e confiança com aqueles que demonstram algum grau de conhecimento do idioma. Assim, essa língua de herança tem como papel manter proximidade e camaradagem nas relações interpessoais entre os colegas, mas também, funciona como exposição de um sentimento de pertença ligado à etnia ucraniana, ou seja, os usos linguísticos por parte do aluno implicam a necessidade de manutenção e reafirmação de sua pertença identitária.

Acerca das últimas colocações, Charaudeau (2009) questiona se essa identidade é individual ou resultado dos diversos tecidos sociais que nos constituem, dos quais, o primeiro condiz ao núcleo 
familiar. Assim, ao pensarmos a problematização de Charaudeau, pensamos nas diversas relações que essa manifestação linguística reflete.

Primeiramente, a relação língua-família e os discursos que se produzem nesses núcleos em relação ao elo língua e identidade, e em segundo, as relações que extrapolam as células familiares e se deslocam para outros ambientes, como a igreja, por exemplo, onde, mais uma vez, a língua ganha um espaço de manutenção e preservação dos discursos que nela são produzidos em busca da manutenção dos costumes, valores, comportamentos e crenças de um grupo.

Ao afirmarmos que o ucraniano transparece, em sala de aula, a manutenção da identidade de um povo, não o fazemos tendo como suporte o plano estrutural da língua. Para tanto, nos embasamos nos ditos de Charaudeau (2009, p. 161), ao postular que a identidade linguística de um grupo é subsidiada pela crença de que a língua constitui a identidade coletiva desse grupo.

O pesquisador concorda que é graças à língua que se produz a coesão social e se constrói o simbolismo identitário, que ela nos faz partícipes de um passado criando uma solidariedade com ele, e faz com que nossa identidade seja parte da história. No entanto, o autor problematiza se de fato é a língua que desempenha a função de pertença identitária ou se este papel cabe aos discursos que nela são produzidos.

A partir disso, o autor propõe dissociar língua e cultura, e então, associar discurso e cultura, pois, se no primeiro caso língua e cultura coincidissem, por exemplo, as culturas francesas quebequense, belga, suíça seriam iguais, bem como a brasileira e a portuguesa.

No son las palabras en su morfología ni las reglas de la sintaxis las portadoras de lo cultural, sino que lo son las maneras de hablar de cada comunidad, los modos de emplear las palabras, la manera de razonar, de narrar, de argumentar, para conversar, para explicar, para persuadir, para seducir. (CHARAUDEAU, 2009, p. 62)
O que o autor pontua em sua fala é o fato de não ser a língua enquanto estrutura o mecanismo desenvolvedor do sentimento de pertença no indivíduo, ou seja, nem a morfologia nem a sintaxe da língua podem ser portadoras de cultura, pelo contrário, são as maneiras de falar de cada comunidade, são os modos de empregar as palavras, de agir e pensar, etc. Assim sendo, a pertença que se efetiva pela língua está ligada aos discursos que nela se produzem.

Nessa perspectiva, ao analisarmos os dados acima, entendemos que as alternâncias linguísticas, sejam elas exolíngues ou multilíngues, não se efetivam em blocos isolados por conta de suas nomenclaturas, pelo contrário, podem acontecer em um mesmo enquadre interacional a depender do contexto comunicativo, dos interlocutores, do assunto em pauta e das necessidades linguísticas e intenções de seus falantes.

Além de possibilitarem a compreensão das práticas linguísticas adotadas em aulas de Língua Estrangeira, os registros acima servem, ainda,como desvelamento da realidade linguística brasileira que se reflete nas salas de aulas, em que as línguas minoritárias, aqui nos referimos ao termo em decorrência do status político a elas atribuído (Ponso, 2017), são infiltradas por seus falantes em contexto escolar, diluindo a concepção de homogeneidade linguística brasileira.

Ao seguirmos com nossas análises, agora, a partir de um exame do excerto abaixo, fragmento 3, conforme a seguir:

Fragmento 3

1. Marcelo: o que que é hambre?

2. Professora: fome! (3 segundos pausa) La última pregunta es: ((Ustedes conocen

3. algo respecto a esto?)) Ya respondemos!É (::) Cómo se llama vó em ucraniano?

4. Alice: baba!

(Tradução: baba/бáбa = vó) 
5. Professora: baba? E babcia é em polonês?

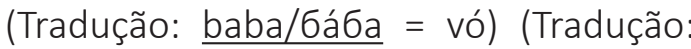
babcia = avó)

6. Antonio: você num sabe?

7. Alice: cumé que é?

8. Professora:babcia!

(Tradução: babcia= avó)

9. Alice: é que tem uns ucranianos, umas pessoas que falam assim as mesmas

10. palavras só que com sotaque diferente sabe?

11. Professora: uhum!

12. Alice: É a mesma palavra só que as vezes eles trocam algumas palavras, o dzia,

13. eles trocam essas palavras bastante daí talvez isso...

14. Professora: dziadzio?

(Tradução: dziadzio ou dziadek= avô)

15. Alice: é, na verdade, é dido!

(Tradução: Didu/ дідусь = Avô)

16. Professora: dido?

(Tradução: Didu/ дідусь = Avô)

17. Alice: é, é dido, mas eles falam dziadzio.

(Tradução: Didu/ дідусь $=$ Avô) (dziadzio ou dziadek= avô)

18. Professora: é em ucraniano que tem umas palavras que não tem vogais daí mesmo assim se pronunciam?

19. Alice: é, é uma letra só que se fala uma palavra.

20. Professora: uhum, uhum!

21. Alice: tipo (:) o alfabeto ele é bem assim xxx djé, jé, xxx tipo é uns desenho as letra, uma palavra lá e se lê djé

22. Professora: talvez como em japonês, chinês que também são letras e a gente num.
23. Alice: é, tem um livro lá que eu fiz o curso daí tem o alfabeto inteiro assim, tem

24. essas palavra.

25. Professora: que bom que você fez o curso lá pra aprendê né. É (:), mi esposo sabe algunas palabras solo en polonés. $Y$ generalmente cuando las personas van a

26. hablar en otra lengua, es para qué?

27. Roberto: para xingá, os outros (risos)

28. Professora: eso! (ri) porque la persona no va a comprender. Si está con una rabia

29. muy grande, entonces habla xxx porque la persona no está comprendiendo.

30. sí! Generalmente los alumnos preguntan algunas palabrotas, que seriam

31. palavrões em espanhol, "cómo se llama esto en español, profesora?" cómo

32. que es eso? Porque de eso no se olvidan. Aquí no ocurrió, pero en las otras

33. escuelas, la primera cosa que preguntan es: "como que é ônibus em español,

34. professora?" E daí como tem vários países que falam espanhol, cada país tem su,

35. supropio nombre, camión, guagua colectivo, ómnibus, autobús, y otros más. $E$

36. daí, "ah, mas tem outro, professora!"Eso no es ómnibus, es micrómnibus!

37. Pequeno ônibus, né! É isso vocês sabem no? (risos) las palabrotas se quedan más

38. fáciles en nuestra cabeza no, Tiago? (risos)

Por meio deste fragmento, percebemos, mais uma vez, os processos de contatos entre as línguas, promovendo os fenômenos de influências e empréstimos linguísticos. Tal afirmação se confirma na fala de Alice (linha 9), em resposta à pergunta da professora (linhas 5 e 8), ao tentar explicar à docente que avó em ucraniano é baba e 
não babcia. Embora saibamos que este referente integra o léxico da língua polonesa, para Alice o vocábulo pertence ao idioma ucraniano.

Para a estudante, os referentes citados fazem parte de um mesmo sistema linguístico, e, sendo assim, o que os diferencia não são as línguas às quais pertencem, mas, o sotaque com que são pronunciados, ou seja, para ela há uma explicação fonética que justifica os empréstimos. Esse posicionamento se estende para os turnos 15 e 17 quando a estudante tenta explicar para a docente que dido e džiadzৃio significam a mesma coisa, avô, e ambas as palavras pertencem ao idioma ucraniano, portanto, as diferenças não estão relacionadas aos sistemas linguísticos distintos, mas, conforme explana, ao "sotaque" com que são pronunciados.

Nessa perspectiva, temos dados que nos dão um panorama da situação linguística do contexto, no qual não existem fronteiras linguísticas demarcando espaços de usos e línguas, pois estas se cruzam e entram em contato o tempo todo, independentemente dos níveis de conhecimentos dos falantes que, a depender da situação comunicativa, de seus objetivos e de suas necessidades linguísticas, lançam mão de todas as línguas a que têm acesso durante a interação. Nesse viés, vemos, mais uma vez, que as fronteiras culturais e linguísticas, vistas ao longo dos anos como demarcadas, vão sendo diluídas pelos processos decorrentes das relações humanas.

No entanto, ainda que a diluição das fronteiras aponte seus aspectos positivos, há um viés negativo que se constrói a partir disso tendo por base os conhecimentos diferenciados dos falantes, pois, conforme mencionado, Alice teve acesso ao conhecimento formal da língua ucraniana (assim como os demais que frequentaram as aulas durantes a catequese) mas não da língua polonesa, o que implica em julgamentos acerca das produções linguísticas ligadas ao último sistema, ou à mescla resultante do contato entre os dois idiomas.
Nesse sentido, quando a adolescente menciona que: "É a mesma palavra só que às vezes eles trocam algumas palavras, o dzia, eles trocam essas palavras bastante daí talvez isso..." (Fragmento 3 , linha 12), torna-se perceptível, que dentro daquilo que costumamos imaginar enquanto comunidade homogênea, há escalonamentos relacionados aos saberes linguísticos, produzindo julgamentos entre os que se reconhecem como constituintes dessa "comunidade", marcando dessa maneira, também as relações humanas entre esses semelhantes.

Assim, o conhecimento da língua também caracteriza a noção de estigma da qual se busca fugir, pois, quanto maior o nível de conhecimento, menores são as chances de ser considerado como "uns ucranianos, umas pessoas que falam assim[...]" (Fragmento 3, linha 9), ou seja, que falam com sotaque, que demonstram um conhecimento diferenciado, superficial, fragmentado e incompleto, aos olhos da estudante.

Ao continuarmos com o estudo dos registros anteriores, percebemos que as intenções da docente não residem somente no plano da aprendizagem das línguas de herança como forma de valorização à diversidade local, mas se estendem e retornam para o ensino da Língua Estrangeira, o espanhol.

Assim, a professora estabelece relação com as discussões que promoveram a negociação do conhecimento nas línguas do entorno e inicia uma explicação acerca da diversidade linguística espanhola atrelada à geografia mundial, mas não às influências decorrentes da proximidade entre português/espanhol e nem mesmo aos empréstimos linguísticos.

Mesmo assim, a reflexão estabelecida acima em torno da variação linguística espanhola, pode ser compreendida como um processo que levará, mesmo que inconscientemente, os alunos a pensarem na diversidade linguística que constitui cada uma de suas línguas, dentre elas, a língua portuguesa. 
Os dados nos mostram que a sala de aula da Língua Estrangeira não deve estar voltada somente para o ensino/aprendizagem da língua e cultura a ela ligadas, mas, que contemple a realidade do contexto em que essa língua é ensinada, seja ele local, regional ou nacional, bem como as realidades que constituem os diversos países e espaços nos quais se fala essa língua em estudo, problematizando também as relações interpessoais e de poder que marcam sua vitalidade. Ainda, podemos entender que esse espaço da sala de aula é um local em que se pode realizar a gestão das línguas em prol da valorização e reconhecimento do repertório linguístico dos alunos e da complexidade sociolinguística do contexto.

\section{Considerações finais}

As práticas pedagógicas usadas para interagir com as turmas possibilitaram o surgimento das línguas de herança em sala de aula, caracterizando interações plurilíngues, baseadas na multiplicidade de posicionamentos, crenças e atitudes voltadas à legitimação de saberes e manutenção de uma identidade etnolinguística, muitas vezes grupal constituídas de escalonamentos.

No entanto, essas práticas de gerenciamento de línguas adotadas na maioria das aulas, também direcionaram os comportamentos linguísticos dos alunos e determinaram quais línguas seriam aceitas na interação, momentos em que se evidenciou uma gestão de línguas orientando usos monolíngues em língua espanhola.

Em outros momentos, dentro dessa mesma prática, flutuava-se para o português, quando uma palavra ou expressão, bem como regulação do comportamento da turma se fazia necessário. Em resposta erguia-se uma gestão de línguas por parte dos estudantes que solidarizavam-se com as posturas docente quando os usos linguísticos se faziam transparentes e de fácil compreensão e adotavam o espanhol em suas falas, mesmo que ligadas a gestos de confirmação e expressões afirmativas. Ora optavam pelo português por julgar seus conhecimentos ainda parciais na língua em aprendizagem ou porque se sentiam mais seguros e à vontade para efetivar réplicas às perguntas da professora. Tais ocorrências, caracterizaram as alternâncias multilíngues em sala.

No entanto, essa gestão de línguas passa por reformulações e as práticas se alternam entre o espanhol e o português e suas variedades, caracterizando as alternâncias de tipo exolíngues. Tais acontecimentos decorrem de necessidades de ajustes na comunicação para uma compreensão geral das explicações quando os usos linguísticos em língua espanhola não se faziam transparentes e compreensíveis a todos, quando uma fala de aluno indicava incompreensão linguística ou de conteúdo.

Ainda, tornou-se perceptível que nas salas de aulas, mesmo que o plurilinguismo enquanto prática social seja constante, em alguns momentos a diversidade linguística, do ponto de vista da variação, é encarada pelo viés monolíngue de ensino. Esta concepção é dirigida por crenças relacionadas aos discursos públicos sobre as linguas, tal como se viu nas análises das respostas dos alunos, mas também, durantes os estudos e exames dos registros das aulas. Assim, parece haver um encobrimento à realidade local quando se trata de ensinar a língua estrangeira, em que cada língua deve ser abordada em blocos isolados.

Essa gestão de línguas, na maioria das ocorrências, teve por base a adoção da língua como forma de mantê-la enquanto objeto de aprendizagem, ações que respondem a uma Política Linguística de Estado, silenciadora. Tal concepção resulta em uma gestão de línguas que não responde à realidade linguística do entorno escolar, logo, a escola age estigmatizando as línguas locais por não entender as representações dessas línguas para seus falantes. 
Com base em nossas discussões e descobertas, entendemos a necessidade de fomento a novas pesquisas em dados contextos para descortinar a realidade linguística brasileira como a da pesquisa, a fim de proporcionar maior visibilidade aos grupos e línguas locais, e, consequentemente, às suas culturas que circulam nas salas de aulas de modo camuflado.

Nesse sentido, entra em jogo a imprescindibilidade da formação docente embasada por uma educação linguística abrangendo:

[...] o conjunto de fatores socioculturais que, durante toda a existência de um indivíduo, lhe possibilitam adquirir, desenvolver e ampliar o conhecimento de/sobre outras línguas, sobre a linguagem de um modo mais geral e sobre todos os demais sistemas semióticos. Desses saberes, evidentemente, também fazem parte as crenças, superstições, representações, mitos e preconceitos que circulam na sociedade em torno da língua/linguagem e que compõem o que se poderia chamar de imaginário linguístico ou, sob outra ótica, de ideologia linguística. Inclui-se também na educação linguística $\mathrm{O}$ aprendizado das normas de comportamento linguístico que regem a vida dos diversos grupos sociais, cada vez mais amplos e variados, em que o indivíduo vai ser chamado a se inserir (BAGNO; RANGEL, 2005, p. 63).

Segundo os autores, dentro dessa perspectiva, pode-se afirmar que a educação linguística de um indivíduo inicia-se em âmbito familiar quando, em suas interações com a família e a comunidade, adquire sua (s) língua (s) materna (s) e, junto com ela (s), progressivamente, toda uma cultura de linguagem característica de seu meio social. Seguindo por essa perspectiva, Bagno e Rangel, em muitas sociedades, como a brasileira, a educação linguística pode ser objeto de uma formalização, de uma sistematização, de uma institucionalização, enfim, promovida pelas instâncias de poder que constituem o aparato estatal, da qual a escola faz parte. Logo, a formação de professores seguida pela perspectiva da educação linguística, tal como pontua Oss (2013), promove nos alunos o conhecimento do outro e de si mesmos através do conhecimento das diferenças e das semelhanças advindas de uma educação linguística que valorize e respeite a diversidade a partir da sala de aula e da própria realidade.

\section{Referências}

ANDRÉ. M. E. D.A.Etnografia da prática escolar. Campinas, SP: Papirus, 1995.

BERGER, I. R. Gestão do multi/plurilinguismo em escolas brasileiras na fronteira Brasil Paraguai: um olhar a partir do Observatório da Educação na Fronteira. 2015. 298f. Tese (Doutorado em Linguística) -Programa de PósGraduação em Linguística, Universidade Federal de Santa Catarina, Florianópolis, 2015.

CALVET, L. J. As Políticas Linguísticas. São Paulo: Parábola, 2002.

CHARAUDEAU, P. Identidad linguística, identidad cultural: una relación paradójica. IN: BUSTOS, J. J. \& IGLESIAS, S. Identidades sociales e identidades linguísticas. Ed. Complutense, Madrid. 2009

HALL, S. A identidade cultural napósmodernidade. Rio de Janeiro: DP\&A, 2006.

KRAUSE-LEMKE，C.Políticas e práticas linguísticas: um estudo sobre o ensino de língua espanhola em um contexto multilíngue no Paraná - Brasil. 2010.Tese (Doutorado) Faculdade de Educação, Universidade de São Paulo, São Paulo, 2010.

MELO-PFEIFER, S. Português como língua de herança: que português? Que língua? Que herança? Domínios de Lingu@gem, Uberlândia, vol. 12, n. 2, abr/jun. 2018.

MELO-PFEIFER, S.; FLORES, C. O conceito de língua de herançana perspectiva da Linguística e da Didática de Línguas: considerações pluridisciplinares em torno do perfil linguístico das crianças lusodescendentes na Alemanha. Domínios de Lingu@gem, Uberlândia, v. 8, n. 3, 
ago./dez. 2014.

MOZZILLO de MOURA, I.Traição lingüística e lealdade cultural - A alternância de código no discurso bilíngüe. 1997. Dissertação (Mestrado em Letras). Universidade Católica de Pelotas, Pelotas- RS, 1997.

MOZZILLO, I. O mito da pureza lingüística confrontado pelo conceito de code-switching. In: Anais do CELSUL 2008. VIII Encontro do CELSUL. 29-31 outubro de 2008, Porto Alegre, RS.

MOZZILLO, I. A conversação bilíngüe dentro e fora da sala de aula de língua estrangeira. In: VETROMILLE-CASTRO, R.; HAMMES W. J. (Orgs.) Transformando a sala de aula, transformando o mundo: ensino e pesquisa em língua estrangeira. Pelotas, EDUCAT, 2001.

PUPP-SPINASSÉ, K. O Hunsrückisch no Brasil: a língua como fator histórico entre Brasil e Alemanha. Espaço Plural. Ano IX. No. 19. p.117-126, 2008.

SHOHAMY, E. Language policy: hidden agendas and new approaches. New York: Routledge, 2006.

SPOLSKY, B. Language Policy: key topics in Sociolinguistics. Cambridge: Cambridge, 2004. E-Book. Disponível em: https://books. google.com.br/books?hl=pt-BR\&lr=\&id=RT $\mathrm{k} 7 \mathrm{gMprn} 1 \mathrm{MC} \& \mathrm{oi}=$ fnd\&pg $=$ PP10\&dq $=$ Lang uage + policy + is + all + about + chooices\&ots $=O$ c1nLdrhLG\&sig=bknNkQxUZAi2O7JnJDG qNf6q_A0\#v=snippet\&q=all $\% 20$ about $\% 20$ chooices\&f=false. Acesso em: 10 marc. 2019.

Submissão: março de 2020. Aceite: março de 2020 